\title{
1. Deepening reform and opening-up for China to grow into a high-income country
}

\section{Ligang Song, Yixiao Zhou and Luke Hurst}

\section{Searching for new engines of growth}

In the past four decades, the Chinese economy has experienced three growth surges. The first took place following the period of 'reform and opening-up' from the late 1970s; the second occurred following the implementation of taxation reforms in 1994; and the third happened after China's accession to the World Trade Organization (WTO) in 2001 (Figure 1.1). Over the entire period of reform (1978-2018), the annual growth rate of the economy was more than 9 per cent and China's per capita income reached US\$9,600 in 2018. Rapid growth in China has led to its economy making up a greater share of both the Asian and the global economies. In 1980, China contributed about 2 per cent of the global economy; in 2018 , this was nearly 16 per cent (Figure 1.2 ). Furthermore, the importance of the Chinese economy is seen not only in its scale, but also in its contribution to global economic growth. In 2018, China was the largest contributor to global economic growth, at 32 per cent; emerging and developing economies excluding China contributed 44 per cent and the advanced economies contributed 24 per cent (Figure 1.3).

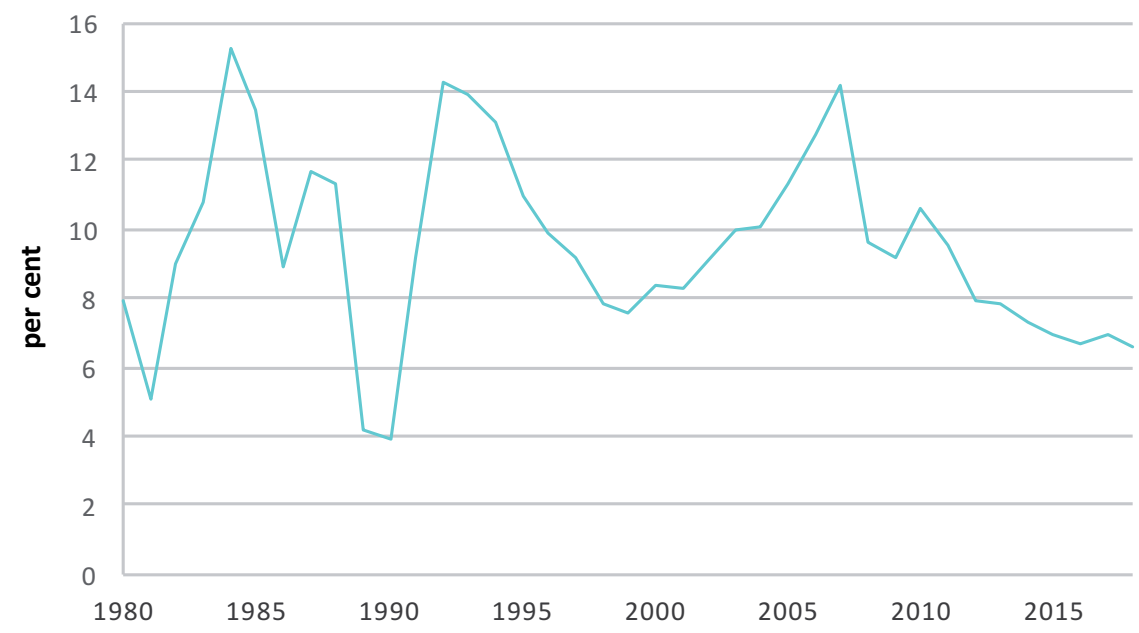

Figure 1.1 Official real GDP growth in China, annual percentage change, 1980-2018

Sources: IMF (various years). 


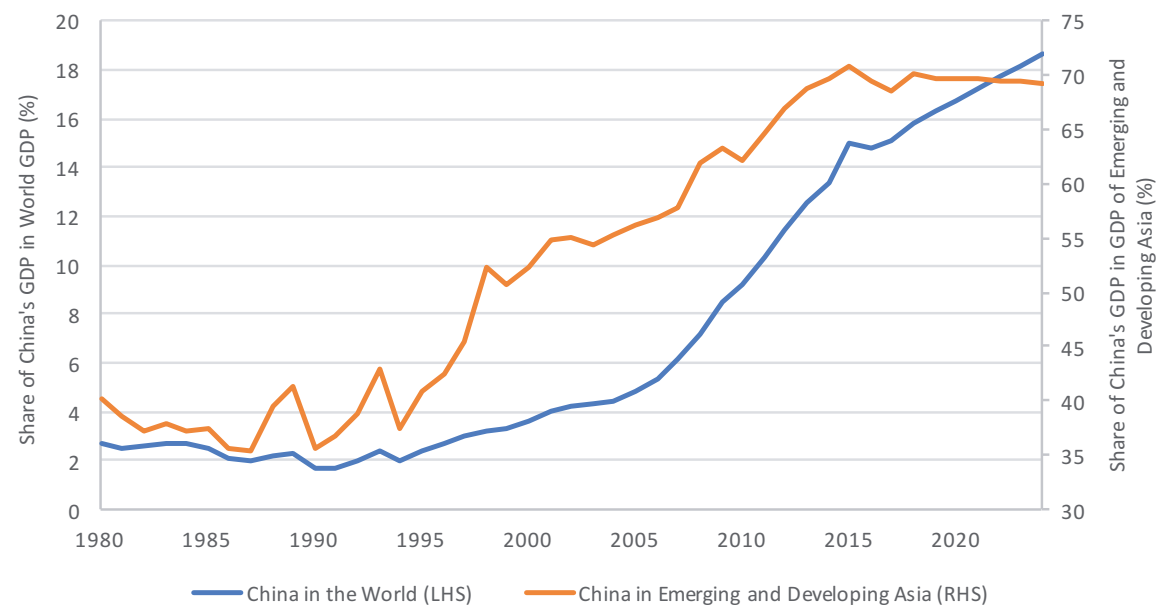

Figure 1.2 China's share of global GDP and of emerging and developing Asia GDP, 1980-2024 (per cent)

Note: Post-2017 data are estimated values.

Source: Authors' calculations based on data for GDP (in current US dollar prices) from IMF (2019).

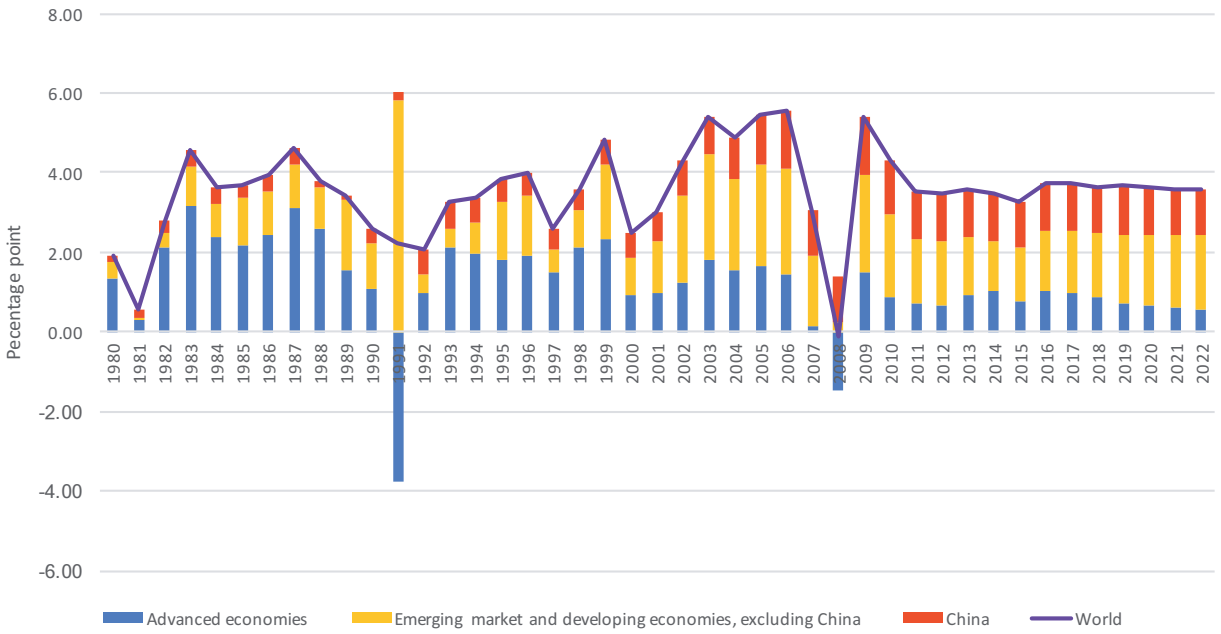

Figure 1.3 Contributions to global growth (yearly average)

Source: Authors' calculations from data on GDP based on the purchasing power parity (PPP) share of the global total and the growth rate of global GDP at constant prices (IMF various years).

While growth in China is still robust, it has been slowing since 2010, as a result of headwinds (Figure 1.1). A question one may ask is whether those headwinds will derail that economic growth and prevent China from reaching high-income status or whether there are ways by which China can overcome these headwinds and continue to grow, albeit at a slower trajectory, in the next phase of its development. In this chapter, we aim to understand some of the causes of the growth slowdown and identify new sources of long-term growth through the lens of growth theories. 
The 'East Asian' growth model allowed several emerging countries and economies to become industrialised and to catch up with the living standards of the advanced economies. This model—featuring openness to trade and investment-has also benefited China since its reform and opening-up policies were introduced, and the Chinese economy has become increasingly integrated with the global economy. During this phase, the main drivers of growth were structural changes in the economy away from the agricultural sector towards the manufacturing and service sectors, which were propelled by fundamental reforms in both rural and urban areas (Figure 1.4). As workers move from rural to urban areas, the increase in labour combines with capital and imported technology to yield rapid productivity growth (Song et al. 2011).

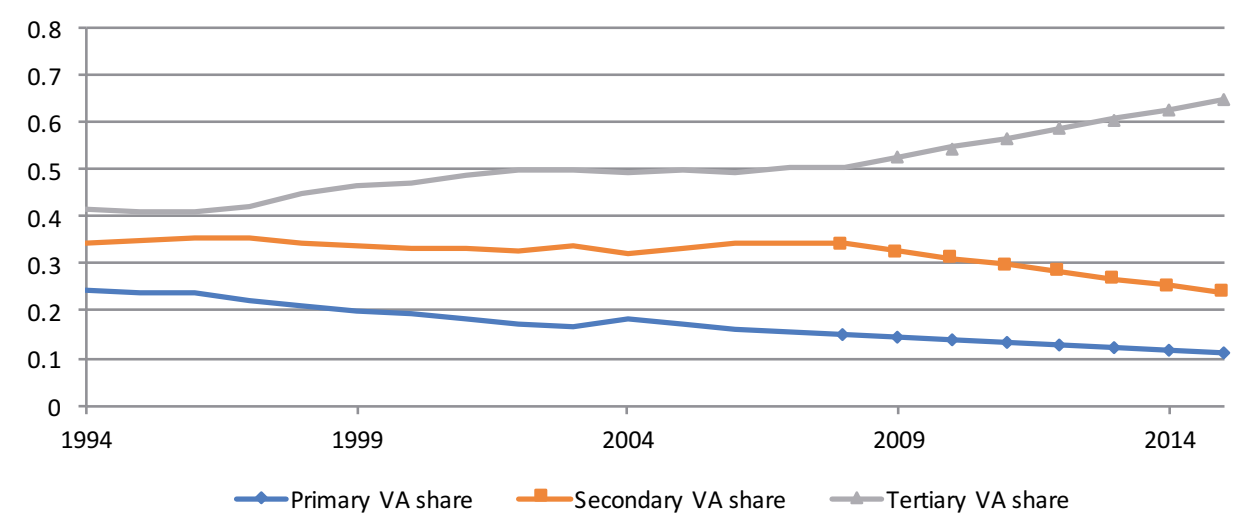

Figure 1.4 Value-added shares by sector in China, 1994-2016

Source: Authors' calculations based on data from WIOD (n.d.).

As China continues to catch up with the technology frontier and move up the global value chains, innovation has become increasingly necessary to sustain productivity growth. As innovation activities pick up, the research and development (R\&D) intensity of the Chinese economy has been rising (Figure 1.5). However, innovation activities are intrinsically risky and the outcomes are often uncertain. Therefore, productivity growth naturally becomes harder to achieve, and this is one of the fundamental causes of the growth slowdown as observed in the continuous drop in China's total factor productivity (TFP) in recent years. 


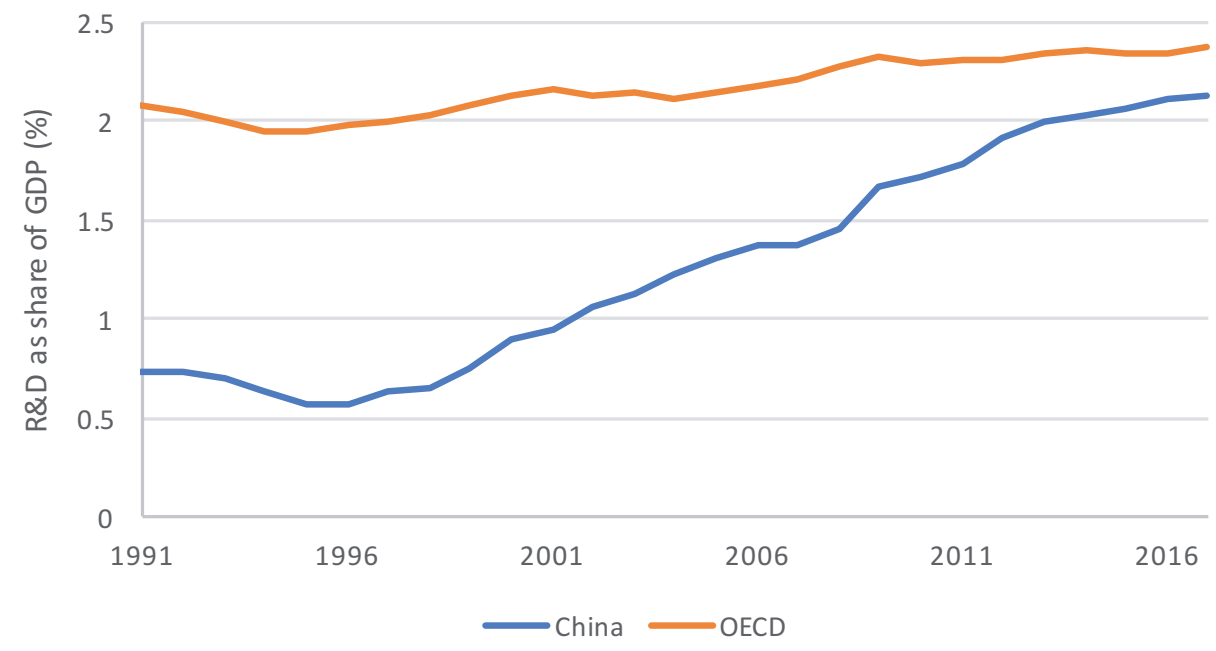

Figure 1.5 Research and development as a share of GDP (per cent) Source: OECD (n.d.).

The second cause of the growth slowdown is China's ageing population, which causes a decline in the share of the working-age population in the total population. The share of those aged 15-64 in the total population reached a peak of 78 per cent in 2010 and has been declining since, to 72 per cent in 2017 (Figure 1.6). This demographic change reduces the labour supply. In the earlier model of growth, focusing on labour-intensive manufacturing production and trade, China relied on a large labour supply. Therefore, transitioning to new engines of sustainable growth and maintaining that growth over the long term will mean relying more on innovation and less on the supply of labour or factor inputs. Furthermore, the ageing population will bring about a lower savings rate, as was observed in Japan (Golley et al. 2018). Although China's previous rapid growth, combined with lagging social institutions and industrial reform, induced a very high savings rate among households and state-owned enterprises (SOEs) (Bayoumi et al. 2012), the savings rate has been falling in the past few years. The national savings rate peaked at 51.5 per cent of GDP in 2010 and fell to 46.4 per cent of GDP in 2017. The decline in the savings rate exerts downward pressure on domestic investment and the current account surplus, as shown in Figure 1.7. 


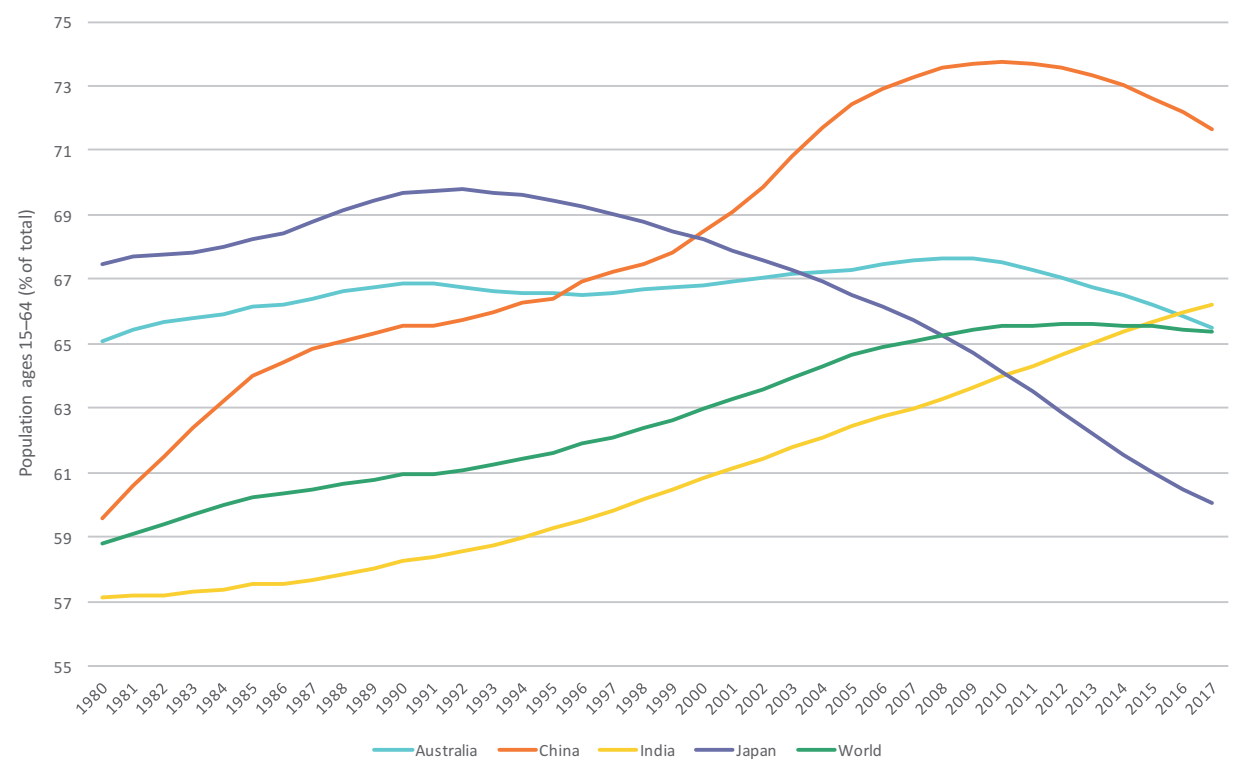

Figure 1.6 Share of population aged 15-64 (percentage of total)

Source: World Bank (2019b).

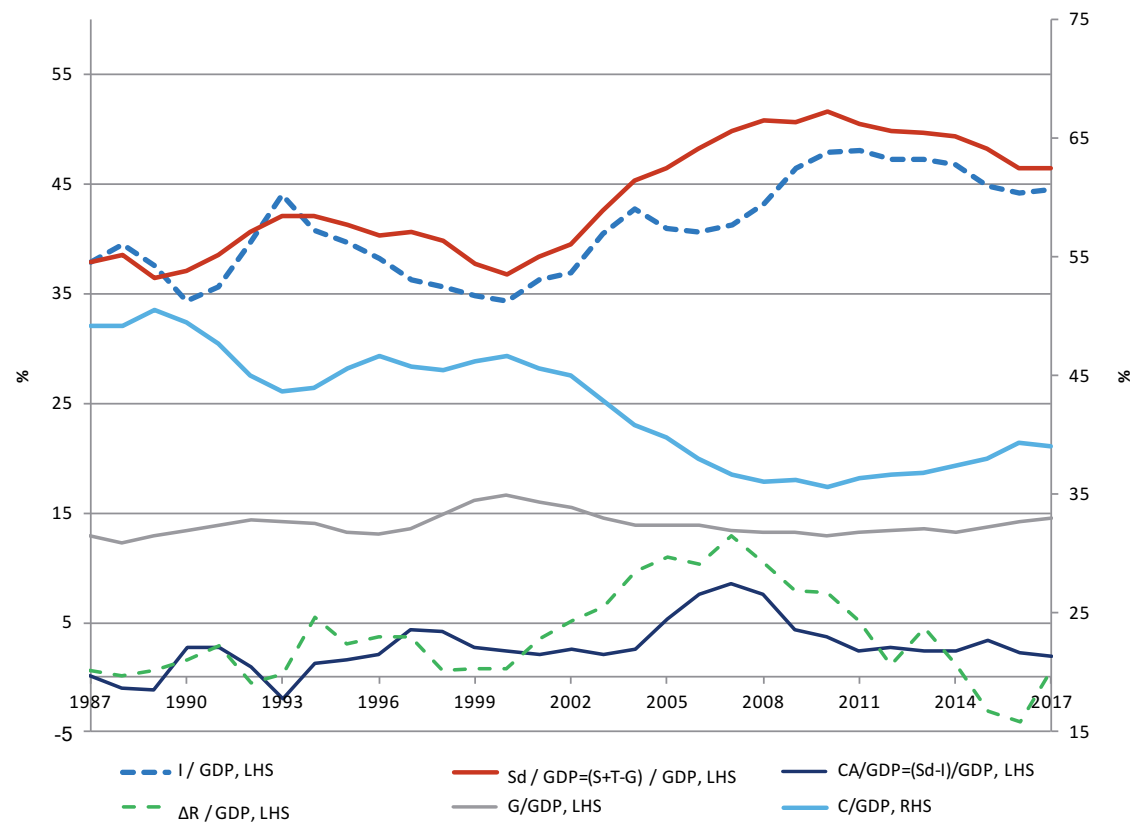

Figure 1.7 Savings, investment and external balance in the Chinese economy, 1987-2017

Note: I, C, CA, G, $\triangle R, S_{d}$ refer to investment, consumption, current account, government purchase, change in reserve, and domestic savings.

Sources: Authors' calculations based on data for the current account and change in official reserves from SAFE (n.d.) and other data from the CEIC Database. 
The above analysis originates from supply-side factors, including technical, institutional and demographic changes. In the short run, demand-side factors also play important roles in determining the growth rate. More subdued investment and net export growth tend to slow GDP growth from the demand side of the growth equation.

Although we see in Figure 1.7 that consumption and government purchases have both grown as shares of GDP since 2010, the more recent data suggest that consumption growth has slowed since the second quarter of 2018 and government purchase is expansionary but cautious (Song and Zhou 2019). Investment growth is slowed both by lower savings growth, as discussed earlier, and by relatively weak business confidence. The contribution of investment growth to GDP growth fell from 2.1 percentage points in the third quarter of 2018 to 0.8 percentage points in the first quarter of 2019. Similarly, net exports weakened due to lower savings growth and the rise in trade tensions between China and the United States. Net export growth was in negative territory in the first three quarters of 2018 and returned to positive values in the fourth quarter of 2018 and the first quarter of 2019 (Figure 1.8).

At this juncture, the key questions are what the new drivers of economic growth will be and how to bring them about. The answer we propose is that there is still great room and scope for further reform to unleash a new round of relatively rapid and high-quality growth, which will allow China to become a high-income economy. We argue that new growth engines are to be found in the following areas. First, deepening institutional reform and improved institutional design and quality will allow the Chinse economy to be integrated more closely into global markets. This will require China, together with its trading partners, to uphold multilateral principles and the international rules-based trading system, and to explore ways in which that system can be reformed to accommodate new patterns of trade and investment flows. This task is especially important given the current trend of deglobalisation with rising protectionism. Second, further opening-up of goods, capital and labour markets and lowering of market barriers are required to expand global collaboration on research, innovation and business activities. Third, further improvements in education and skill levels and reduction in poverty are needed to enhance equality of opportunity and alleviate rising income inequality. There is still a significant gap between China and the advanced economies in terms of education levels and technical capability. Therefore, there will be significant room for Chinese talent to contribute more to the global technology pool. 


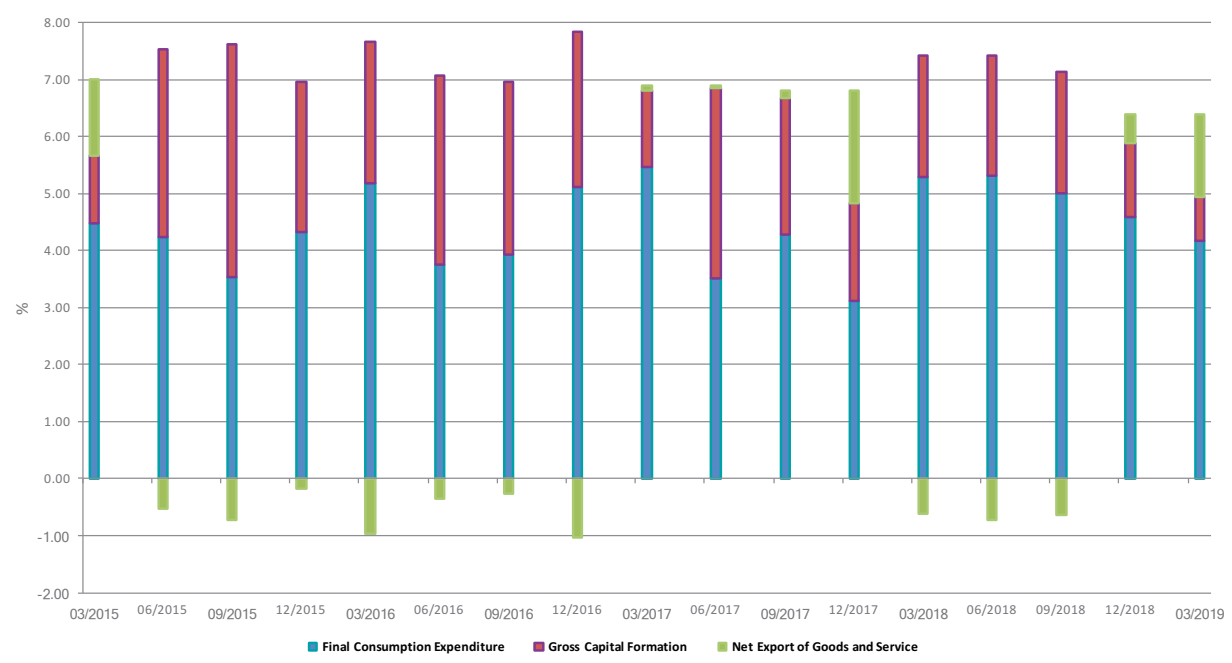

Figure 1.8 Contributors to GDP growth in China, 2015Q3-2019Q1 Source: CEIC Database.

From the perspective of growth theories, it is worth noting that these reforms will help deliver endogenous technological and institutional innovations that will lead to higher productivity growth in the long run. It is well understood that the ultimate long-run driver of a country's growth performance is productivity growth (Solow 1956; OECD 2012). Also, importantly, contributions to the global technology pool can benefit all countries' technological progress and economic growth under market mechanisms (Jones and Romer 2010).

The first piece of evidence of the significant room for China to improve its business and institutional environments comes from the 'Doing Business' statistics reported by the World Bank (2019a). In 2019, the statistics for China are based on surveys conducted in Shanghai, one of the most mature commercial and international metropolitan cities in mainland China. The results show that China ranked 46 out of 190 countries and regions on the overall Ease of Doing Business Score. In comparison, the Hong Kong Special Administrative Region ranks fourth among all countries and regions. The more detailed rankings for various aspects of doing business provide a further sense of where the most stringent bottlenecks are and where future institutional and policy reforms can be focused (Figure 1.9). 


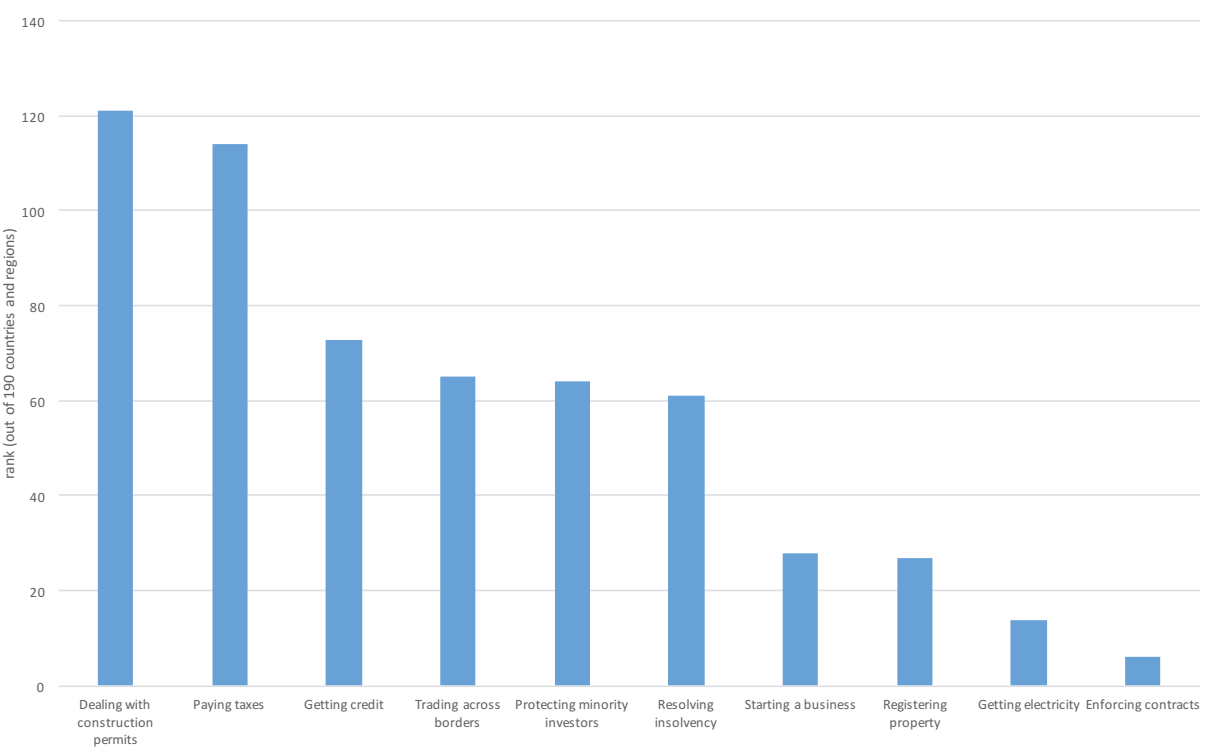

Figure 1.9 Ease of doing business rankings for China, 2019 Source: World Bank (2019a).

A positive development in enhancing the institutional environment is that a set of new policies has recently been introduced. One example of these is the introduction of the principle of 'competitive neutrality' in the 'Guiding Opinions on Promoting the Healthy Development of Small and Medium-Sized Enterprises' recently issued by the General Office of the Communist Party of China Central Committee and the General Office of the State Council (The State Council 2019). The guidelines require the implementation of policies that help small and medium-sized enterprises (SMEs) compete fairly in markets. Specifically, the guidelines emphasise policies that include lowering barriers to market entry, creating fair competition, providing easier access to credit, lowering the tax and regulatory burden, enhancing innovation, encouraging private entrepreneurship and reducing the influence of political connections.

The essence of the principle of competitive neutrality is that all actions taken by the government should have a neutral impact on market competition between SOEs and other enterprises - that is, government actions do not favour any actual or potential market participation. In particular, SOEs should not have an improper competitive advantage resulting from government policies or regulations. The principle of competitive neutrality was originally proposed by Australia in 1996 (Commonwealth of Australia 1996). At the time, it was stated that government commercial enterprises should not enjoy a net competitive advantage over their private sector competitors simply because they were owned by the government. This concept was later also explored in policy research conducted by the Organisation for Economic Co-operation and Development (OECD). Broadly summarised, there 
are four aspects of the concept: 1) in the case of SOEs providing public services or undertaking public policy functions, they should be given fair and transparent compensation for their costs; 2) there should be equal treatment of SOEs and other enterprises in regulation and government procurement; 3) in debt financing, SOEs should not benefit from explicit or implicit state guarantees; and 4) in equity financing, the state as a shareholder requires SOEs to provide market return on investment (Capobianco and Christiansen 2011). China has now adopted the concept of competitive neutrality in reforming its SOEs and nurturing the private sector. The United States has already applied the concept to the binding rules of its bilateral trade negotiations such as its free-trade agreement with Singapore, the new North American Free-Trade Agreement, the Trans-Pacific Partnership and the ongoing negotiations with Japan and the European Union, and between China and the European Union in terms of bilateral investment treaty negotiations.

Another encouraging development is the introduction of policies to further open markets to foreign investment. In financial markets, these measures include removing limits on the foreign ownership of local banks, scrapping size limits for foreign firms and allowing foreign insurance groups to set up in China. Under the new plans for financial liberalisation, the upper shareholding limits in a Chinese commercial bank for a single Chinese-funded bank or a single foreign-funded bank will be abolished simultaneously (Yu 2019). The National People's Congress adopted the new Foreign Investment Law in March 2019. Under this law, the principle of non-discrimination will be added to administrative approval procedures, along with increased financial penalties imposed on those who infringe trademark rights. In the meantime, the procedures and time it takes to receive construction permits will be sharply reduced (Hu 2019).

The above policies are aimed at helping attract overseas investment and helping China remain one of the world's leading destinations for foreign direct investment (FDI). After China's WTO accession, an unprecedented accumulation of foreign investment, combined with new access to markets in the advanced economies, delivered another growth surge in the country. However, there is still scope for foreign investment to contribute further to China's economic growth. And there is great potential in financial integration and opening-up to help enhance China's growth. Figure 1.10 shows that, although FDI in China has experienced very strong growth, its share in total investment in China has declined since 1994. As savings rates fall in China, more foreign investment will help generate investment and growth activities. 


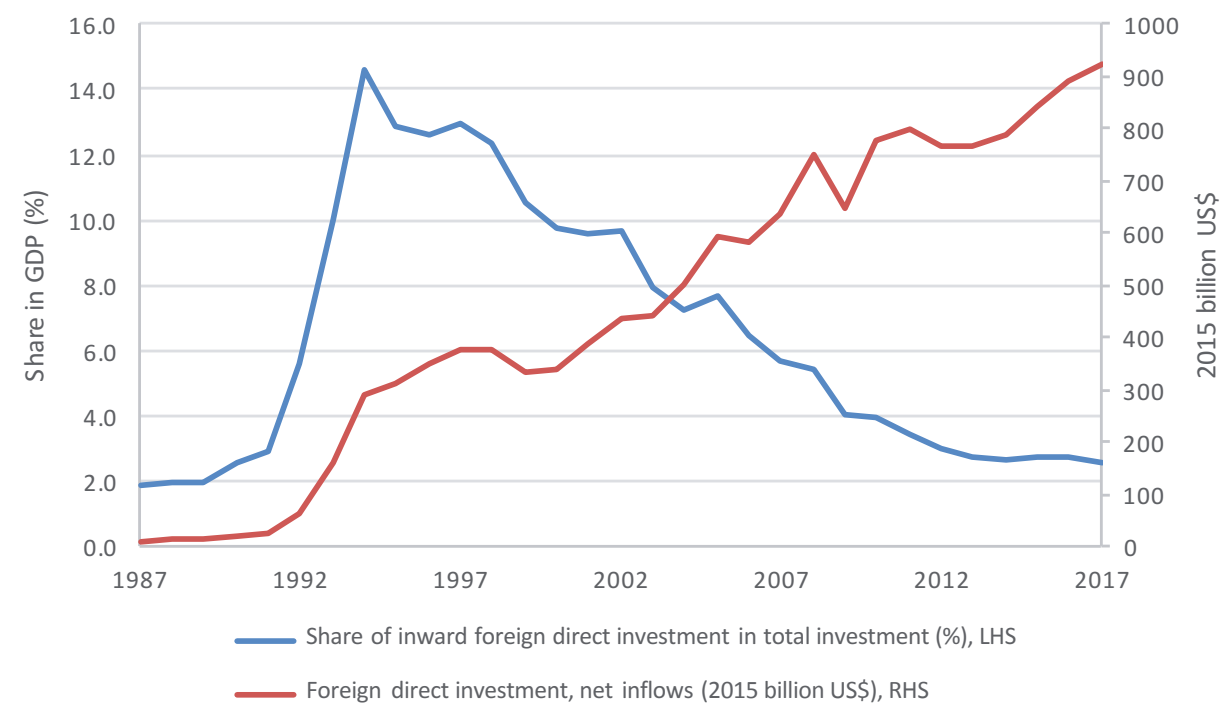

Figure 1.10 FDI inflows and its share of total domestic investment in China (per cent)

Notes: We obtain data for inward FDI as share of GDP in China. We calculate total domestic investment as a share of GDP in China. We then calculate the share of FDI inflows in total domestic investment by dividing the former by the latter. For the red series, real GDP is calculated in constant 2015 US dollars. This is then multiplied by the share of inward FDI in GDP to obtain inward FDI in constant 2015 US dollars. Sources: Authors' calculations based on data from CEIC Database; IMF (various years); UNCTAD (n.d.).

Using new policy levers to move towards a more open, transparent and fair market environment for all firms and to link and integrate domestic and international rules for commerce will help the Chinese economy integrate more deeply and smoothly into the global market. It is well understood that trade helps firms stay competitive by exerting constant pressure to innovate and improve the quality of products and services in the international market (Bernard et al. 2007; Zhou and Song 2016). Furthermore, competing with foreign firms in the domestic market has similar effects. Although the contribution of net exports to GDP growth may wind down as a result of economic rebalancing towards more consumption-driven growth, the importance of openness extends beyond raising GDP and rests more on driving productivity growth.

Besides improvements in the institutional environment, another source of future growth is boosting the education and skill levels of individuals (Khor et al. 2016). Despite China's significant achievements in enhancing education, the Chinese economy still suffers a shortage of human capital compared with many other developing and advanced economies. Comparing the share of the labour force that has attained at least some upper secondary schooling (upper secondary attainment) in China with that in other countries (for example, high-income/OECD countries and a subset of G20 middle-income/Brazil, Russia, India, China and South Africa), Khor et al. (2016) find that, in 2010, only 24 per cent of China's entire labour 
force (individuals aged 25-64 years) had ever attended upper secondary school, and this rate was less than one-third of the average in OECD countries. China's overall upper secondary attainment rate and the attainment rate of its youngest workers (aged 25-34) are also the lowest of the BRICS countries (Brazil, Russia, India, China and South Africa), with the exception of India, for which data were not available. As human capital is critical for innovation and knowledge-based growth, continued investment in education and skills should be a policy priority.

This book consists of contributions from young economists who have closely researched the latest developments in the Chinese economy. Their new analytical perspectives and findings help us better understand and identify future directions for the Chinese economy, as seen through the eyes of the young.

\section{Structure of the book}

The book begins with a chapter by Guiying Laura Wu that details the challenges of capital allocation China is facing after 40 years of reform. To frame the discussion, Wu provides a comprehensive survey of the existing literature to construct a general framework with which to investigate the interaction of financial frictions and policy distortions with TFP loss. The chapter discusses the quantitative implications of aggregate efficiency loss within such a framework. Wu concludes that the structural reforms that are particularly relevant to capital misallocation are mainly those in the enterprise sector and the financial system. These findings provide a guide for future reforms to improve capital allocation.

Chapter 3 uses an impressive set of data, including 4 million Chinese manufacturing company samples from 1998 to 2013, to understand debt and credit misallocation in Chinese corporations. The authors-Ninghua Zhong, Mi Xie and Zhikuo Liufind that, during the 16-year period analysed, most firms were deleveraging, with the simple average and median of debt ratio decreased from 65 per cent in 1998 to 51 per cent in 2013'. Of the companies that increased their leverage, most were large-scale, listed SOEs. Interestingly, the authors find that the characteristics of private firms change with the changes to leverage, but those of SOEs do not. The authors conclude that the huge amount of credit being allocated to the state sector is the reason for the declining credit efficiency in China.

The authors suggest that the 'main battlefield for deleveraging is the state-owned sector, especially inefficient and large enterprises, which usually have severe overcapacity', and the government should therefore promote market-oriented reforms of SOEs. But these SOE reforms need to be complemented by increased leverage in efficient areas with market-oriented reforms of commercial banks and other financial intermediaries so that valuable credit resources can be allocated to productive enterprises. 
There is rising concern about the economic slowdown occurring in China. In Chapter 4, Jiao Wang and Ran Li develop an extension of the standard New Keynesian dynamic stochastic general equilibrium model to understand China's monetary policy, along with the main causes of fluctuations in the country's business cycle, providing a novel way of examining the rules governing China's monetary policy. Using a hybrid form of monetary policy rule, the authors find that the People's Bank of China adjusts the policy rate in response to inflation, output growth and real money growth. Neutral technology shocks are the main drivers of the fluctuations in output and consumption, while investment-specific technology shocks are the primary source of variations in investment. Wang and Li conclude that, after more than 30 years of driving high-speed economic development, a structural break in the development of neutral technology may have caused China's GDP growth to slow since 2010. This conclusion points to the need for the Chinese Government to encourage technological innovation and industrial upgrading.

In Chapter 5, Yuhan Zhao, Moyu Chen and Yu Sheng use extensive farm household survey data to investigate the evolution of the household registration (bukou) system at the provincial level between 1981 and 2013, and to understand its impact on off-farm employment in rural China. The authors also make a significant contribution by compiling a comprehensive indicator to capture the transtemporal and cross-regional changes in the household registration system during the postreform period. The analysis finds that off-farm employment of rural labour increased with the relaxation of household registration policies during the post-reform period; this is particularly the case for full-time off-farm employment. The analysis implies that barriers related to the hukou system still prevent the integration of rural and urban labour markets.

Following on from the previous chapter's analysis of the impact of hukou reforms on off-farm employment, Chapter 6 investigates the growth, scale and characteristics of nonstandard employment (NSE) in China. Analysis of the 2016 China Urban Labour Survey (CULS), undertaken by Yongjie Wang, contributes three important findings: first, the proportion of NSE in urban China in 2016 was 34.95 per cent, indicating that NSE has become an important feature of China's labour market. Second, those working in NSE in China have comparably low levels of job satisfaction, low wages, high overtime rates, low social insurance coverage and inadequate wage rights protection. Third, labourers with lower levels of educational attainment, age disadvantages and those who are unmarried and have rural bukou are more likely than others to engage in NSE. Wang argues that targeted policies need to broaden the employment choices for those who are more likely to engage in NSE and measures need to be taken to strengthen the collective bargaining power of NSE workers by, for example, absorbing nonstandard workers into labour unions. 
The development of rural e-commerce in China could unlock significant economic benefits, including more inclusive growth, poverty alleviation and inequality reduction. In Chapter 7, Sherry Tao Kong explores the ways in which the Chinese Government has 'not only allowed space for digital companies to experiment, but also introduced a wide range of policies and projects to improve the country's internet infrastructure to promote the development of e-commerce'. Through her analysis of the growth of Taobao villages across China, the author finds that the promise of e-commerce for rural development in China is not guaranteed: 'Reliable internet access, trustworthy digital transaction methods and convenient parcel delivery and logistics services are necessary but insufficient conditions to realise the promise of e-commerce in less-developed areas.' It also requires organic grassroots growth and supportive top-down policies.

Since the end of 2012, the Chinese Government has implemented a number of policies aimed at helping the country become a global leader in innovation. In Chapter 8, Zhongyu Ma, Huiqing Gao, Weihua Yin and Zhichao Wen use local survey data to understand the impact of these policies and the potential for improvement. The authors find that policies to promote innovation are working well. China is, however, in the early stages of innovation development and, consistent with theory, it is experiencing interruptions that slow progress. Two such interruptions include inconsistencies in the issuing of intellectual property policy and incomplete policy implementation. While China's innovation is currently in its initial phase_-characterised by high investment - the authors suggest that these upfront costs will produce high yields in coming years.

In Chapter 9, Liqing Zhang, Yan Zhang and Zhixiao Dong investigate the effects of China's financial services liberalisation on the financial constraints of China's listed firms. The authors set up an exogenous policy measure of China's financial service liberalisation based on a thorough policy review. Using the latest panel data (for the period 2010-15), the analysis shows that China's financial liberalisation has diminished the financial constraints on the country's listed firms; notably, China's formal external financing channels through banks and other financial institutions have been enhanced by trade credit, especially for larger firms. The analysis also supports the idea that financial liberalisation eliminates ownership discrimination.

The development of China's SMEs is vital to the country's future economic growth, job creation and innovation. In Chapter 10, Qin Gou and Yiping Huang analyse whether the SME financial support scheme has effectively promoted banks' credit allocation to SMEs. The authors use a unique bank branch survey dataset to analyse the impact of the policy. The analysis suggests there have been mixed outcomes, with increased lending to SMEs that fell short of the initial loan requirements, while other SMEs that exceeded the initial loan requirements received smaller loans. 
On the costs of the scheme, Gou and Huang note that it increases the credit risk of small banks and decreases their profits. The authors suggest the business, financial and innovation environments need to be fundamentally improved.

One of the biggest threats to the global economy is the escalating trade war between the United States and China. In Chapter 11, Deborah H.Y. Tan and Chen Chen use the G-cubed multi-country model to understand the potential costs of the China-US trade war and suggest ways to mitigate them. The findings suggest that a bilateral trade war will impose larger costs on China in the short term, while the United States will suffer a similar adverse impact on growth in the medium term. The authors note that, while the current policy approach of the Chinese Government of matching tariffs is the 'sensible and conservative option that cushions the economy adequately in the near to medium terms, while reducing the chances of international repercussions', the government has more severe options available, such as redeploying US holdings, if it is 'pushed into a very tight corner'.

In Chapter 12, Jane Golley, Yixiao Zhou and Meiyan Wang investigate the level of equal opportunity in the annual labour income of Chinese individuals, with a focus on the role of gender. In their analysis of data from the 2010 Survey of Chinese Women's Social Status, the authors show that 'gender is the number one determinant of unequal opportunities, ahead of socioeconomic, regional and urban-rural divides'. The analysis goes on to assess the underlying causes of gender earnings inequality; this micro-analysis indicates that gender (via returns on education) and marriage are the most significant determinants of the gender income gap. Based on the findings, Golley, Zhou and Wang offer a number of important policy recommendations, including targeting education policies at girls from poor rural families, assisting young women to exit the agricultural sector and find offfarm employment and ongoing reform to the hukou system.

As Chinese companies invest overseas in larger numbers and on larger projects, they are encountering a number of political obstacles in host countries. In Chapter 13, Bijun Wang and Xiao He provide one of the first empirical investigations into Chinese outward direct investment (ODI) projects that have been blocked. Using a unique dataset, the authors find that several factors increase the likelihood of an investment being blocked, including large scale, technological intensity and a poor bilateral relationship with the host country. Given these characteristics are commonly associated with blocked investments, Wang and Xiao recommend several strategies to reduce the probability of Chinese projects encountering obstacles, including breaking large-scale investments into multiple smaller investments, focusing on industries that receive less public and government scrutiny and increasing intellectual property protections and $R \& D$ spending in host countries. 
The final chapter by Luke Hurst follows on from Chapter 13 by providing a detailed case study of Chinese investment during the iron ore boom. The chapter considers two important questions: Does access to state capital reduce the ability of others to compete in the market? And is the Chinese state using capital to lock up strategic resources?

Using a unique dataset of 50 iron ore procurement arrangements, the findings suggest that state-owned financing institutions were involved in the majority of investments and most investments were undertaken by central and provincial-level SOEs in concert with non-Chinese partners. However, Chinese iron ore investors were most often operating outside their core competency and lacked long-run ownership advantages. The lack of iron ore development and operating competence meant they generally paired with a non-Chinese specialised fringe iron ore producer. The preference for quasi-integration through joint ventures with non-Chinese fringe iron ore producers means that Chinese state support effectively lowered barriers to market entry for non-Chinese fringe iron ore miners. On the second question, the application of a scorecard approach to the procurement data found that, instead of tying up resources, China's aggregate iron ore procurement arrangements have led to a broadening of the competitive global supply base and increased access to iron ore for other buyers in the Asian market, as did the Japanese procurement arrangements in the 1970s and 1980s. This finding is consistent with research on Chinese oil procurement.

\section{References}

Bayoumi, T., Tong, H. and Wei, S.J. (2012), The Chinese corporate savings puzzle: A firm-level cross-country perspective, Working Paper No. 202012, Hong Kong: Hong Kong Institute for Monetary Research, available from: EconPapers.repec.org/RePEc:hkm:wpaper:202012.

Bernard, A.B., Jensen, J.B., Redding, S.J. and Schott, P.K. (2007), Firms in international trade, Journal of Economic Perspectives 21(3): 105-30. doi.org/10.1257/jep.21.3.105.

Capobianco, A. and Christiansen, H. (2011), Competitive neutrality and state-owned enterprises: Challenges and policy options, OECD Corporate Governance Working Paper No. 1, Paris: Organisation for Economic Co-operation and Development, available from: www.oecd-ilibrary.org/docserver $/ 5 \mathrm{~kg} 9 x f g j d h g 6-e n . p d f$ expires $=1559644294 \& \mathrm{id}=\mathrm{id} \&$ accname $=$ guest $\&$ checksum $=784 \mathrm{BBA6AF} 1 \mathrm{~A} 94075 \mathrm{~A} 5 \mathrm{BBCB} 546658 \mathrm{~F} 3 \mathrm{E} 2$.

Commonwealth of Australia (1996), Commonwealth Competitive Neutrality Policy Statement, June, Canberra: Department of Treasury, available from: archive.treasury.gov.au/ documents/275/PDF/cnps.pdf.

Golley, J., Tyers, R. and Zhou, Y. (2018), Fertility and savings contractions in China: Long-run global implications, The World Economy 41(11): 3194-220. doi.org/10.1111/ twec. 12602. 
Hu, Y. (2019), Foreign businesses get assurance as new trade rules ensure equality, Policy Watch, 9 April, Beijing: The State Council of the People's Republic of China, available from: english.gov.cn/policies/policy_watch/2019/04/09/content_281476600762343.htm.

International Monetary Fund (IMF) (various years), World Economic Outlook, Washington, DC: IMF.

International Monetary Fund (IMF) (2019), World Economic Outlook Database, April, Washington, DC: IMF, available from: www.imf.org/external/pubs/ft/weo/2019/01/ weodata/index.aspx.

Jones, C.I. and Romer, P.M. (2010), The new Kaldor facts: Ideas, institutions, population, and human capital, American Economic Journal: Macroeconomics 2(1): 224-45. doi.org/ 10.1257/mac.2.1.224.

Khor, N., Pang, L., Liu, C., Chang, F., Mo, D., Lovalka, P. and Rozelle, S. (2016), China's looming human capital crisis: Upper secondary educational attainment rates and the middle-income trap, The China Quarterly 228: 905-26. doi.org/10.1017/ S0305741016001119.

Organisation for Economic Co-operation and Development (OECD) (n.d.), OECD Database, Paris: OECD Publishing, available from: data.oecd.org/.

Organisation for Economic Co-operation and Development (OECD) (2012), Looking to 2060: A global vision of long-term growth, OECD Economics Department Policy Notes No. 15, Paris: OECD Publishing.

Solow, R. (1956), A contribution to the theory of economic growth, The Quarterly Journal of Economics 70(1): 65-94. doi.org/10.2307/1884513.

Song, L. and Zhou, Y. (2019), A balanced macroeconomic approach could be China's panacea, East Asia Forum, 6 March, available from: www.eastasiaforum.org/2019/03/06/ a-balanced-macroeconomic-approach-could-be-chinas-panacea/.

Song, Z., Storesletten, K. and Zilibotti, F. (2011), Growing like China, American Economic Review 101: 202-41. doi.org/10.1257/aer.101.1.196.

State Administration of Foreign Exchange (SAFE) (n.d.), Data and Statistics, Beijing: SAFE, available from: www.safe.gov.cn/en/.

The State Council of the People's Republic of China (2019), Guiding Opinions on Promoting the Healthy Development of Small and Medium-Sized Enterprises, Beijing, available from: www.gov.cn/zhengce/2019-04/07/content_5380299.htm.

United Nations Conference on Trade and Development (UNCTAD) (n.d.), Statistics database, Geneva: UNCTAD, available from: unctad.org/en/Pages/statistics.aspx.

World Bank (2019a), Doing Business: Measuring business regulations, Washington, DC: The World Bank Group, available from: www.doingbusiness.org/en/rankings. 
World Bank (2019b), World Bank Open Data, Washington, DC: The World Bank Group, available from: data.worldbank.org/.

World Input Output Database (WIOD) (n.d.), available from: www.wiod.org/home.

Yu, C. (2019), Opening-up to boost finance sector, Policy Watch, 4 May, Beijing: The State Council of the People's Republic of China, available from: english.gov.cn/policies/policy _watch/2019/05/04/content_281476643005930.htm.

Zhou, Y. and Song, L. (2016), International trade and R\&D investment: Evidence from Chinese manufacturing firms, China and World Economy 24(1): 63-84. doi.org/10.1111/ cwe.12144. 
This text is taken from The Chinese Economic Transformation: Views from Young Economists, edited by Ligang Song, Yixiao Zhou and Luke Hurst, published 2019 by ANU Press, The Australian National University, Canberra, Australia.

doi.org/10.22459/CET.2019.01 